\title{
Project portfolio selection of banking services using COPRAS and Fuzzy-TOPSIS
}

\author{
C.O. Anyaeche ${ }^{a}$, D.E. Ighravwe ${ }^{b^{*}}$ and T.A. Asokeji ${ }^{a}$
}

${ }^{a}$ Department of Industrial and Production Engineering, University of Ibadan, Nigeria

${ }^{b}$ Department of Mechanical Engineering, Ladoke Akintola University of Technology, Nigeria

\section{H R O N I C L E}

Article history:

Received: March 5, 2017

Received in revised format: May

16, 2017

Accepted: June 28, 2017

Available online:

June 28, 2017

Keywords:

Multi-criteria decision-making,

project portfolio selection

Fuzzy-TOPSIS

COPRAS

Banking system

\section{A B S T R A C T}

Portfolio selection is a business process which has helped organisations identify an area of competitive advantage and it is a major concern to industrial players in the banking sectors. In order to enhance bank portfolio selection, cost, profitability, time and location are important parameters that decision-makers often consider. This study implements a fuzzy-TOPSIS (Technique for Order Preference by Similarity to Ideal Solution) framework to evaluate three potential portfolios (automated teller machine gallery, quick service point and branch) for a bank using the information from three decision-makers. An illustrative example of real bank information is used to demonstrate the proposed framework applicability. The complex proportional assessment of alternatives (COPRAS) method is also used as an evaluation technique and the results are compared, which yields that the results from the ranking order of fuzzy-TOPSIS and COPRAS were different. However, there is a consistency between the aggregation of intuition-based, fuzzy-TOPSIS and COPRAS ranks and fuzzy-TOPSIS ranking results. The presented framework is an easy-to-apply tool that improves portfolio selection decision in the banking system.

\section{Introduction}

A project can be defined as a one short time-bound major activity demanding the commitment of varied skills and resources to achieve a specific goal (Telsang, 2012; Anyaeche \& Okwara, 2011). In today's technology-driven society, most organisations embark upon various projects in order to achieve their strategic objectives. However, a paucity of resources compels them to make a choice among the many alternatives in order to arrive at the optimum mix of projects which would enable them to achieve their corporate strategies. The mix of projects which an organisation chooses to execute may determine its success or failure in the market place (Wit, 1998; Anyaeche \& Okwara, 2011). Hence, portfolio management is essential to ensure proper estimation, evaluation and selection of an optimal mix of projects in line with corporate strategy of the organisation (McFarlan, 1981; Wideman, 1995). Therefore, there is a need for systematic and scientific framework for portfolio selection when considering service system (such as financial systems). This is because high capital outlay is often involved during the execution of projects in this type of system.

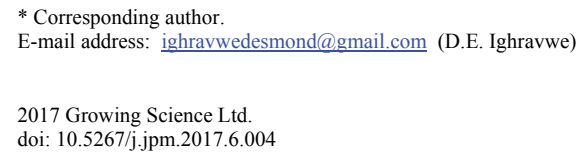


The financial sector is considered to be very crucial to in any economy. The productivity of bank-based financial service institutions impacts on every stratum of an economy. Banking is an evolutionary concern which has expanded its services to include issuance of debit and credit cards and online banking services. Other services of banking systems are provision of Automated Teller Machines (ATM), Point of Sale (PoS) platforms and safe custody of valuable items among others. To capture an appreciable portion of a market, a bank must open up branches in areas where it considers strategic to the realisation of its goals and objectives. However, the choice of branch deployment projects, which a bank may undertake in a particular financial year, is largely determined by resource availability, regulations of the supervising bank and government policy on construction of banks in specific areas. Other constraints to banks operations are construction approval, legal and political dynamics, disposition of host communities to the project, climatic conditions and soil types among others. Therefore, there is a need for an effective framework for evaluating, prioritising and selecting projects in line with the corporate strategy of a bank and within its budget for the financial year.

The plethora of challenges in the management of bank portfolio selection has led to several studies which attempt to address the problem (Paris, 2005; Saunders et al., 2007; Malek et al., 2014; Al-Halaseh et al., 2016; Sirignano et al., 2016). Several attempts at addressing portfolio selection problems have considered the application of Markowiz theorem (Markowiz, 1968), multi-objective linear programming, goal programming, fuzzy linear programming and linear programming models (Malek et al., 2014). Oyatoye et al. (2010) analysed Nigeria capital market using analytic hierarchy process (AHP) (Saaty, 1980). In their study, the issues of bank stability, risks and returns assessment, investment rules and stock market portfolio were considered. Their study outcomes show that there was a need for government intervention in order to prevent the collapse of the Nigeria banking system. Agarana et al. (2014) presented a mathematical model for loan portfolio management that considered the branches, yield on loan, deposit and non-performing loans. Goal programming techniques was used to solve their proposed model. Based on the findings of their study, it was reported that long-term mortgage was one of the major parameters that should be considered during the management of bank's loan portfolio analysis. Sirignano et al. (2016) analysed the problem of large-scale loan portfolio selection using an approximated optimisation technique. The work was able to address the issue of non-linearity and computational time of portfolio selection models. Al-Tarawneh and Khataybeh (2015) adopted Hicks' portfolio choice theory (i.e., expected utility method) to analyze commercial banks portfolio in Jordan. In their study, emphasis was given to own-rate, cross-rate and interest rate as well as non-choice items. Their results revealed that assets holding of bank portfolio composition of Jordan's bank were not affected by new banks. Malek et al. (2014) presented a linear programming approach to portfolio selection. The focus of their study was on the optimisation of facility sales. Based on their results, they deduced that improvement in capital returns could be achieved with the use of mathematical model for bank's portfolio selection. Misra (2011) reported a mathematical model for portfolio selection using a genetic algorithm approach. In the study, the issue of optimal values for portfolio risk and return was investigated. Despite several attempts at addressing bank portfolio selection problems, sparse information on multi-criteria tools exists. This knowledge gap motivated the need for the current study. The aim of this study study is to develop and apply fuzzy Technique for Order Preference by Similarity to Ideal Solution (TOPSIS) technique and Complex Proportional Assessment of Alternatives (COPRAS) methodology for project portfolio selection of banking services. Thus could yield the ranking of the alternatives using multiple criteria.

\section{Methodology}

\subsection{Conceptual framework}

Project selection is a multi-criteria decision-making problem which includes both qualitative and quantitative factors. In order to obtain an optimal mix of projects, trade-offs are usually made between tangible and intangible factors. In project portfolio selection, deliberate efforts are made to estimate, evaluate and choose an optimal mix of projects to be executed within a given period (Anyaeche \& Okwara, 
2011). Anyaeche and Asokeji (2016) employed an integrated approach involving TOPSIS (Yoon \& Hwang, 1995) and AHP, to address decision making in non-precise situations. The project selection process determines the optimum mix of projects. Hence, the need for a priority system to assist in selecting a mix of projects that best contributes to the organisation's objectives, within the constraints of the resources is required (Larson et al., 2011).

The project selection methods (Fig. 1) are streamlined into two main paths. The paths are benefit measurement method (comparative approach) and constrained optimisation method (mathematical approach). Benefit measurement method compares possible projects and selects the best mix of projects executable. Measuring benefits realisation involves collection, consolidation and analysis of data to determine whether stakeholders have been able to realise expected benefits from a planned change. Benefit reviews include Murder Boar, peer review, scoring models and economic models.

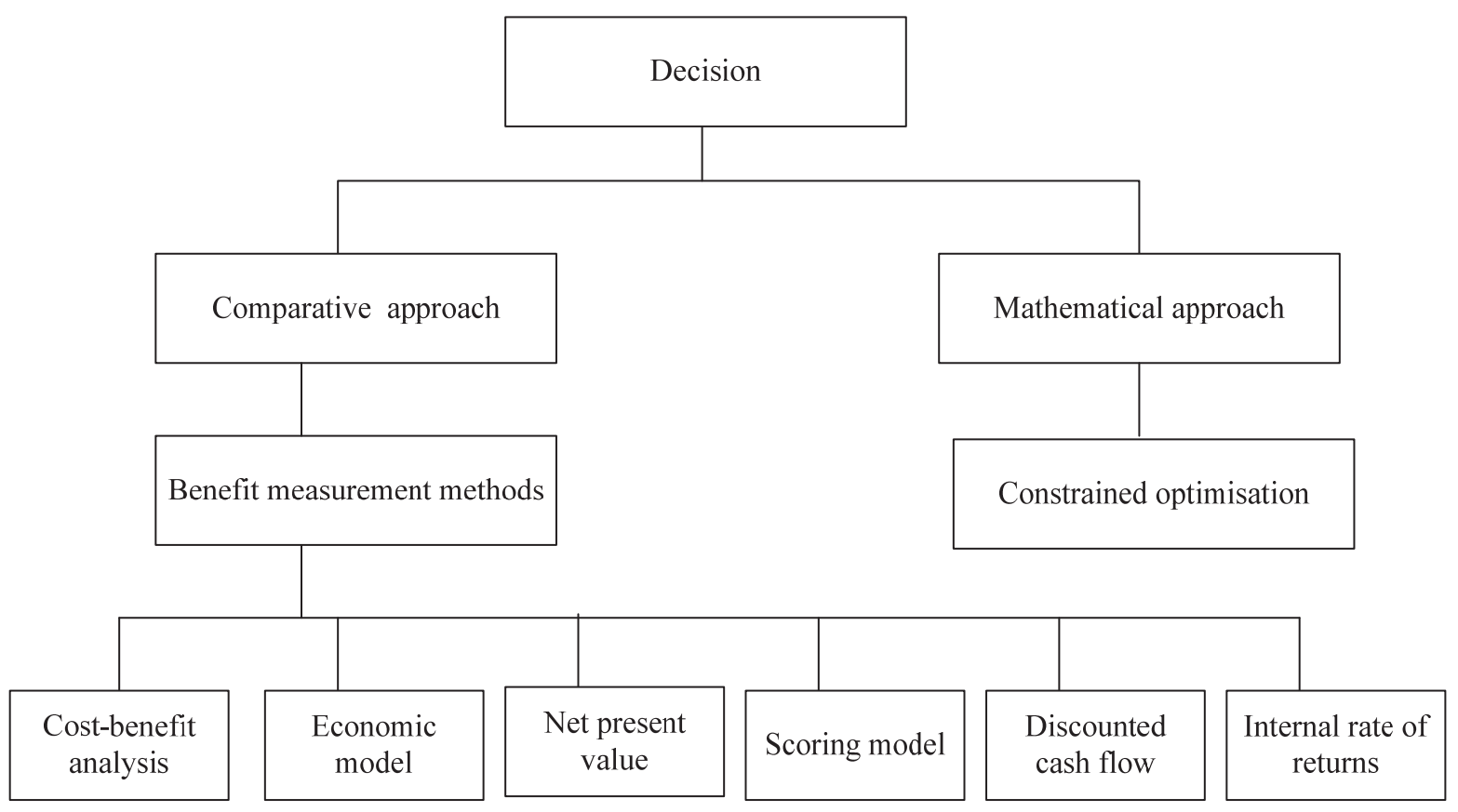

Fig. 1. Project selection criteria (Source: Anyaeche \& Asokeji, 2016)

Constrained optimisation method performs mathematical calculations using various constraints and parameters to produce the probability and outcome to choose projects. Examples include linear programming, integer programming, dynamic programming, multi-object programming. Benefit measurement method is commonly used for project selection in banks because it uses financial criteria such as present value, net present value, internal rate of return, payback period, benefit cost ratio among others to evaluate projects.

The general structure of the proposed framework is shown in Fig. 2. In order to create a reliable framework, this study combines fuzzy TOPSIS and COPRAS methods outputs. A framework that integrates different solution methods has the benefit of producing a good basis for sound decisions (Archer \& Ghasemzadeh, 1999). 


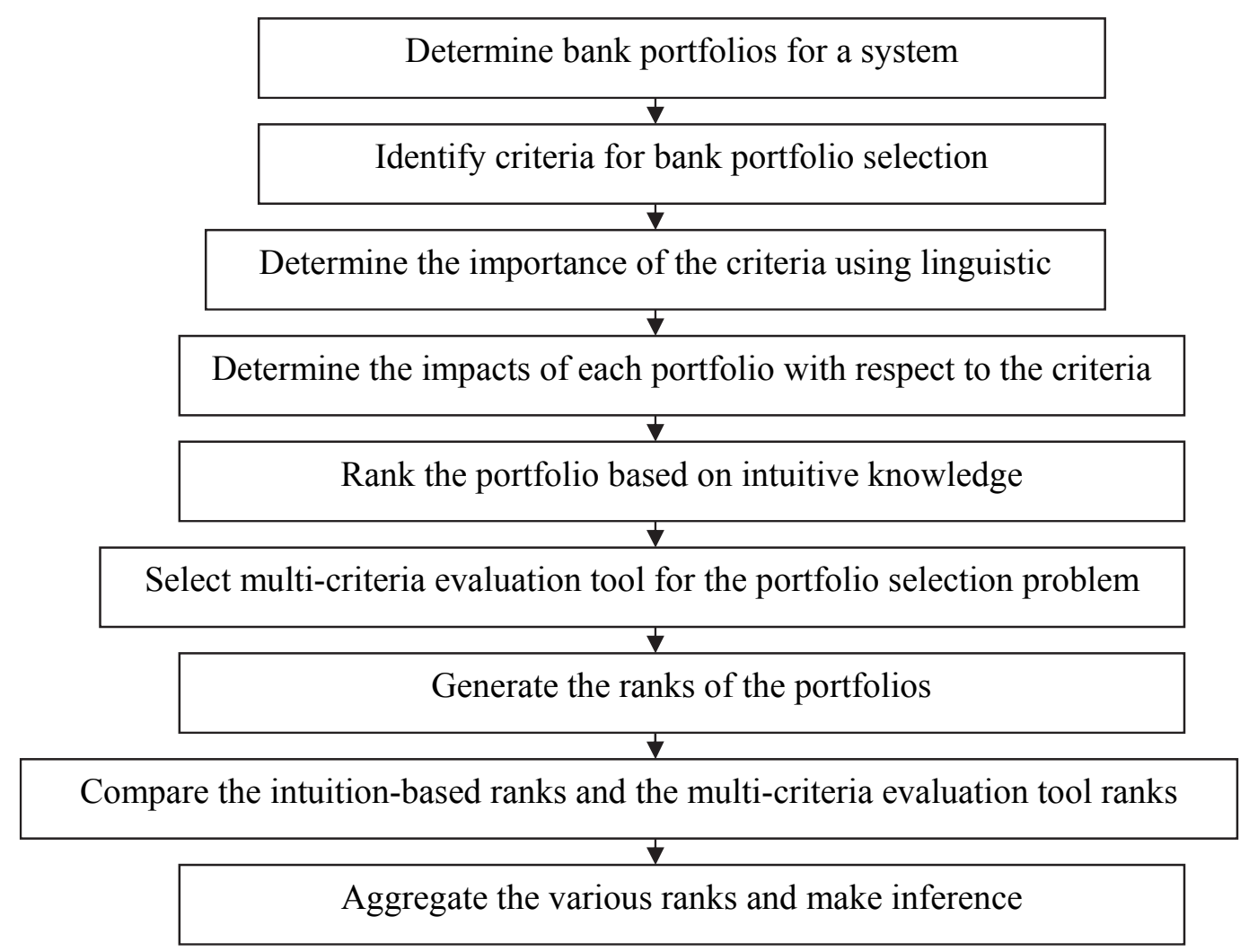

Fig. 2. Conceptual framework for bank portfolio selection

\subsection{Technique for Order Preference by Similarity to Ideal Solution}

TOPSIS method is a goal-based decision-making approach for finding the alternative that is closest to the ideal solution. In this method, options are graded based on ideal solution similarity. If an option is more similar to an ideal solution, it has a higher grade. TOPSIS method is a multiple criteria method that is used to identify solutions from a finite set of alternatives. The basic principle is that the chosen alternative should have the shortest distance from the positive ideal solution and the farthest distance from the negative ideal solution. The procedure of TOPSIS is summarized as follows:

(i) Calculate the normalised decision matrix. In order to generate the normalised decision matrix, the fuzzy numbers assigned to each parameter by decision makers are aggregated using Eqs. (1-4),

$$
\begin{aligned}
& n_{i j 1}=\min \left(n_{i j k 1}\right) \\
& n_{i j 2}=\frac{1}{D} \sum_{d=1}^{D} n_{i j 2} \\
& n_{i j 3}=\frac{1}{D} \sum_{d=1}^{D} n_{i j 3} \\
& n_{i j 4}=\operatorname{Max}\left(n_{i j k 4}\right)
\end{aligned}
$$

The normalised values are calculated based on the desired direction of a parameter. Parameters that are benefit-oriented are normalised using Eq. (5), while Eq. (6) is used as the normalisation expression for cost-oriented parameter. 


$$
\begin{aligned}
& \bar{n}_{i j 1}, \bar{n}_{i j 2}, \bar{n}_{i j 3}, \bar{n}_{i j 4}=\frac{n_{i j 1}}{\max _{j}\left(\bar{n}_{i j 4}\right)}, \frac{n_{i j 2}}{\max _{j}\left(\bar{n}_{i j 4}\right)}, \frac{n_{i j 3}}{\max _{j}\left(\bar{n}_{i j 4}\right)}, \frac{n_{i j 4}}{\max _{j}\left(\bar{n}_{i j 4}\right)} \\
& \bar{n}_{i j 1}, \bar{n}_{i j 2}, \bar{n}_{i j 3}, \bar{n}_{i j 4}=\frac{\min _{j}\left(\bar{n}_{i j 1}\right)}{n_{i j 4}}, \frac{\min _{j}\left(\bar{n}_{i j 1}\right)}{n_{i j 3}}, \frac{\min _{j}\left(\bar{n}_{i j 1}\right)}{n_{i j 2}}, \frac{\min _{j}\left(\bar{n}_{i j 1}\right)}{n_{i j 1}}
\end{aligned}
$$

(ii) Calculate the weighted normalised decision matrix. To generate a weighted normalised decision matrix, the fuzzy weights are combined with the normalised decision matrix. First, the fuzzy numbers for each weight with respect to the number of decision-makers are aggregated. Based on Shemshadi et al. (2011) study as well as Ighravwe and Oke (2016), the fuzzy aggregated trapezoidal numbers for a criterion is obtained using Eqs. (1-4). The expression for an alternative normalised value is given as Eq. (7).

$$
x_{i j 1}, x_{i j 2}, x_{i j 3}, x_{i j 4}=\bar{n}_{i j 1} w_{i j 1}, \bar{n}_{i j 2} w_{i j 2}, \bar{n}_{i j 3} w_{i j 3}, \bar{n}_{i j 4} w_{i j 4}
$$

(iii) Calculate the separation measures, using the n-dimensional Euclidean distance. The separation of each alternative from the ideal solution is given as Equations (8) and (9). The evaluation of the criteria distances from positive ideal solutions is expressed as Equation (8), while the determination of the criteria values from negative ideal solution is obtained using Equation (9). In this analysis, the value of a positive ideal solution is taken as $(1,1,1,1)$, while $(0,0,0,0)$ is taken as the negative ideal solution (Wang \& Elhag, 2006; Madi \& Tap, 20011).

$$
\begin{aligned}
& D_{i}^{+}=\sqrt{\left(x_{i j 1}-v_{j 1}^{+}\right)^{2}+\left(x_{i j 2}-v_{j 2}^{+}\right)^{2}+\left(x_{i j 3}-v_{j 3}^{+}\right)^{2}+\left(x_{i j 4}-v_{j 4}^{+}\right)^{2}} \\
& D_{i}^{-}=\sqrt{\left(x_{i j 1}-v_{j 1}^{-}\right)^{2}+\left(x_{i j 2}-v_{j 2}^{-}\right)^{2}+\left(x_{i j 3}-v_{j 3}^{-}\right)^{2}+\left(x_{i j 4}-v_{j 4}^{-}\right)^{2}}
\end{aligned}
$$

(iv) Calculate the relative closeness to the ideal solution. This is carried out by considering the distances of the alternatives positive and negative ideals solutions (Eq. (10)).

$$
C_{i}=\frac{D_{i}^{-}}{D_{i}^{+}+D_{i}^{-}}
$$

(v) Rank the preference order. The best-ranked alternative is the alternative with the highest relative closeness value.

\subsection{COPRAS}

The quality of decisions during multi-criteria analysis has been aided with the use of multi-criteria technique including COPRAS, ANP, AHP, and TOPSIS. COPRAS method which is based on the analysis of the positive and negative outputs of alternative (Zavadskas \& Kaklauskas, 1996) has not been considered for bank portfolio section to the best of our understanding. COPRAS methodology has similarities with most multi-criteria tools. The first similarity is the use of normalisation expression to convert real data into general ranges. This is necessary in order to eliminate the influence of data with large values on final results after the data analysis. The generally used normalisation expression for COPRAS method is given as Eq. (11).

$$
\bar{x}_{i j}=\frac{x_{i j}}{\sqrt{x_{i j}^{2}}}
$$


The second similarity of COPRAS with existing multi-criteria tools is criteria weights consideration. The weights which are used during COPRAS implementation can be obtained using AHP or ANP. There is the possibility of using fuzzy weights for COPRAS implementation. This is necessary when the information that is used for its implementation is expressed as fuzzy numbers. A common approach for combining weights with their respective crisp values is given as Eq. (12).

$$
\tilde{x}_{i j}=w_{i} \bar{x}_{i j}
$$

where $x_{i j}$ stands for the crisp value of factor $j$ with respect to criteria $i, \bar{x}_{i j}$ stands for the normalised value of factor $\mathrm{j}$ with respect to criteria $i$, and $\tilde{x}_{i j}$ stands for the weighted normalised value of factor $j$ with respect to criteria $i$.

The weighted values of the information for COPRAS method implementation is used to evaluate the positive optimisation directions of the alternatives that are being evaluated (Eq. (13)).

$$
p_{j}=\sum_{j=1}^{n_{1}} \tilde{x}_{i j}
$$

The values that are considered are those that contribute positively towards the attainment of the system's objectives. Parameters whose contributions towards system goals are negative are used to compute the negative optimisation directions of the alternatives (Eq. (14)),

$$
R_{j}=\sum_{j=n_{1}+1}^{n} \tilde{x}_{i j}
$$

where $R_{j}$ stands for the value of factor $j$ negative optimisation direction, and $P_{j}$ stands for the value of factor $j$ positive optimisation direction.

Based on the positive and negative optimisation directions of the alternatives, priority weights for the alternatives are determined (Eq. (15)).

$$
Q_{j}=P_{j}+\frac{\sum_{j}^{n} R_{j}}{R_{j} \sum_{j}^{n} \frac{1}{R_{j}}}
$$

where $\mathrm{Q}_{\mathrm{j}}$ represents factor $\mathrm{j}$ priority weight.

These weights form the basis upon which decisions are made on the most suitable solution method for a problem. To take a decision, the utility degree of each alternative is determined using Eqs. (16-17). The most suitable alternative is the alternative with the highest value of utility degree (Zolfani et al., 2012),

$$
\begin{aligned}
& Q_{\max }=\max \left\{Q_{j}\right\} \\
& N_{j}=\frac{Q_{j}}{Q_{\max }} * 100 \%
\end{aligned}
$$

where $N_{j}$ is utility degree of alternative $j$.

$$
x_{i j}=\frac{x_{i j 3} x_{i j 4}-x_{i j 2} x_{i j 1}+\frac{1}{3}\left(x_{i j 3}-x_{i j 4}\right)^{2}-\frac{1}{3}\left(x_{i j 2}-x_{i j 1}\right)^{2}}{x_{i j 3}+x_{i j 4}-x_{i j 2}-x_{i j 1}}
$$




\section{Application}

In this work, project portfolio selection was examined based on five inputs membership functions i.e., five benefit and cost criteria are considered, namely project success potential $\left(\mathrm{C}_{1}\right)$, profitability $\left(\mathrm{C}_{2}\right)$, time $\left(\mathrm{C}_{3}\right)$, location $\left(\mathrm{C}_{4}\right)$ and cost $\left(\mathrm{C}_{5}\right)$. Also scope with its three categories of membership functions namely, automated teller machine $\left(\mathrm{x}_{1}\right)$ gallery, quick service point $\left(\mathrm{x}_{2}\right)$ and branch $\left(\mathrm{x}_{3}\right)$.

Using fuzzy logic, two multi-criteria decision-making techniques were used namely, AHP and TOPSIS. A committee of three decision-makers $\left(D_{1}, D_{2}\right.$, and $\left.D_{3}\right)$ was constituted to select the most suitable projects from the options proposed for implementation in a given financial year. $\mathrm{D}_{1}$ the chief financial officer, $\mathrm{D}_{2}$ the chief strategy officer $(\mathrm{CSO})$ and $\mathrm{D}_{3}$ the Head, General Services.

Data were collected from Mafabet bank, with over 700 branches nationwide. Usually, most project selection decisions are taken at top management and middle management level without due recourse to appropriate project portfolio selection techniques. Consequently, some of the projects decisions may be at variance with a strategic goal of the bank. About forty per cent of construction projects undertaken is observed to overrun in terms of scope, time or cost. One of the major causes of this high rate of project failure is traceable to the use subjective and vague criteria in selecting project portfolio (Westney, 2004).

\section{Table 1}

Weighted decision rating

\begin{tabular}{lc}
\hline Linguistic terms & Trapezoidal fuzzy number \\
\hline Very low & $(0,0,0.1,0.2)$ \\
Low & $(0.1,0.2,0.2,0.3)$ \\
Medium low & $(0.2,0.3,0.4,0.5)$ \\
Medium & $(0.4,0.5,0.5,0.6)$ \\
Medium high & $(0.5,0.6,0.7,0.8)$ \\
High & $(0.7,0.8,0.8,0.9)$ \\
Very high & $(0.8,0.9,1,1)$ \\
\hline
\end{tabular}

Table 2

Weighted decision matrix

\begin{tabular}{lccc}
\hline Criterion & $\mathrm{D}_{1}$ & $\mathrm{D}_{2}$ & $\mathrm{D}_{3}$ \\
\hline $\mathrm{C}_{1}$ & $(0.7,0.8,0.8,0.9)$ & $(0.7,0.8,0.8,0.9)$ & $(0.7,0.8,0.8,0.9)$ \\
$\mathrm{C}_{2}$ & $(0.8,0.9,1,1)$ & $(0.8,0.9,1,1)$ & $(0.8,0.9,1,1)$ \\
$\mathrm{C}_{3}$ & $(0.8,0.9,1,1)$ & $(0.8,0.9,1,1)$ & $(0.7,0.8,0.8,0.9)$ \\
$\mathrm{C}_{4}$ & $(0.7,0.8,0.8,0.9)$ & $(0.7,0.8,0.8,0.9)$ & $(0.7,0.8,0.8,0.9)$ \\
$\mathrm{C}_{5}$ & $(0.7,0.8,0.8,0.9)$ & $(0.7,0.8,0.8,0.9)$ & $(0.7,0.8,0.8,0.9)$ \\
\hline
\end{tabular}

Table 3

Aggregated fuzzy trapezoidal number for the criterion

\begin{tabular}{lcccc}
\hline Criterion & $w_{i j 1}$ & $w_{i j 2}$ & $w_{i j 3}$ & $w_{i j 4}$ \\
\hline $\mathrm{C}_{1}$ & 0.70 & 0.80 & 0.80 & 0.90 \\
$\mathrm{C}_{2}$ & 0.80 & 0.90 & 1.00 & 1.00 \\
$\mathrm{C}_{3}$ & 0.70 & 0.87 & 0.93 & 1.00 \\
$\mathrm{C}_{4}$ & 0.70 & 0.80 & 0.80 & 0.90 \\
$\mathrm{C}_{5}$ & 0.70 & 0.80 & 0.80 & 0.90 \\
\hline
\end{tabular}


Table 3 was transformed from the ratings of the three project types (ATM, branch and QSP) by the decision makers under all criteria with the following rating scale:

\section{Table 4}

Linguistic terms and fuzzy numbers for the portfolio rating

\begin{tabular}{lc}
\hline Linguistic terms & Trapezoidal fuzzy number \\
\hline Very poor & $0,0,1,2$ \\
Poor & $1,2,2,3$ \\
Medium poor & $2,3,4,5$ \\
Fair & $4,5,5,6$ \\
Medium good & $5,6,7,8$ \\
Good & $7,8,8,9$ \\
Very good & $8,9,10,10$ \\
\hline
\end{tabular}

Three decision makers used the linguistic rating variables to evaluate the ratings of projects with respect to each criterion. The results are summarized in Tables 5-6.

Table 5

The ratings of the three candidates

\begin{tabular}{llccc}
\hline Criterion & & $\mathrm{x}_{1}$ & $\mathrm{x}_{2}$ & $\mathrm{x}_{3}$ \\
\hline \multirow{2}{*}{$\mathrm{C}_{1}$} & $\mathrm{D}_{1}$ & $\mathrm{MG}$ & $\mathrm{G}$ & $\mathrm{VG}$ \\
& $\mathrm{D}_{2}$ & $\mathrm{MG}$ & $\mathrm{G}$ & $\mathrm{VG}$ \\
& $\mathrm{D}_{3}$ & $\mathrm{MG}$ & $\mathrm{G}$ & $\mathrm{G}$ \\
\hline \multirow{2}{*}{$\mathrm{C}_{2}$} & $\mathrm{D}_{1}$ & $\mathrm{MG}$ & $\mathrm{VG}$ & $\mathrm{VG}$ \\
& $\mathrm{D}_{2}$ & $\mathrm{MG}$ & $\mathrm{VG}$ & $\mathrm{G}$ \\
\hline \multirow{3}{*}{$\mathrm{C}_{3}$} & $\mathrm{D}_{3}$ & $\mathrm{MG}$ & $\mathrm{VG}$ & $\mathrm{VG}$ \\
& $\mathrm{D}_{1}$ & $\mathrm{G}$ & $\mathrm{VG}$ & $\mathrm{VG}$ \\
& $\mathrm{D}_{2}$ & $\mathrm{G}$ & $\mathrm{VG}$ & $\mathrm{G}$ \\
\hline \multirow{3}{*}{$\mathrm{C}_{4}$} & $\mathrm{D}_{3}$ & $\mathrm{G}$ & $\mathrm{G}$ & $\mathrm{VG}$ \\
& $\mathrm{D}_{1}$ & $\mathrm{G}$ & $\mathrm{VG}$ & $\mathrm{VG}$ \\
& $\mathrm{D}_{2}$ & $\mathrm{G}$ & $\mathrm{VG}$ & $\mathrm{VG}$ \\
\hline \multirow{2}{*}{$\mathrm{C}_{5}$} & $\mathrm{D}_{3}$ & $\mathrm{G}$ & $\mathrm{VG}$ & $\mathrm{G}$ \\
& $\mathrm{D}_{1}$ & $\mathrm{G}$ & $\mathrm{VG}$ & $\mathrm{VG}$ \\
& $\mathrm{D}_{2}$ & $\mathrm{G}$ & $\mathrm{VG}$ & $\mathrm{G}$ \\
\hline & $\mathrm{D}_{3}$ & $\mathrm{G}$ & & \\
\hline
\end{tabular}

Table 6

Fuzzy decision matrix

\begin{tabular}{lcccc}
\hline Criterion & & $\mathrm{x}_{1}$ & $\mathrm{x}_{2}$ & $\mathrm{x}_{3}$ \\
\hline \multirow{3}{*}{$\mathrm{C}_{1}$} & $\mathrm{D}_{1}$ & $(5,6,7,8)$ & $(5,6,7,8)$ & $(5,6,7,8)$ \\
& $\mathrm{D}_{2}$ & $(7,8,8,9)$ & $(7,8,8,9)$ & $(7,8,8,9)$ \\
& $\mathrm{D}_{3}$ & $(8,9,10,10)$ & $(8,9,10,10)$ & $(7,8,8,9)$ \\
\hline \multirow{2}{*}{$\mathrm{C}_{2}$} & $\mathrm{D}_{1}$ & $(5,6,7,8)$ & $(5,6,7,8)$ & $(8,9,10,10)$ \\
& $\mathrm{D}_{2}$ & $(8,9,10,10)$ & $(8,9,10,10)$ & $(8,9,10,10)$ \\
& $\mathrm{D}_{3}$ & $(8,9,10,10)$ & $(7,8,8,9)$ & $(7,8,8,9)$ \\
$\mathrm{C}_{3}$ & $\mathrm{D}_{1}$ & $(7,8,8,9)$ & $(7,8,8,9)$ & $(7,8,8,9)$ \\
& $\mathrm{D}_{2}$ & $(8,9,10,10)$ & $(8,9,10,10)$ & $(8,9,10,10)$ \\
& $\mathrm{D}_{3}$ & $(8,9,10,10)$ & $(8,9,10,10)$ & $(7,8,8,9)$ \\
$\mathrm{C}_{4}$ & $\mathrm{D}_{1}$ & $(7,8,8,9)$ & $(7,8,8,9)$ & $(7,8,8,9)$ \\
& $\mathrm{D}_{2}$ & $(7,8,8,9)$ & $(8,9,10,10)$ & $(8,9,10,10)$ \\
& $\mathrm{D}_{3}$ & $(8,9,10,10)$ & $(8,9,10,10)$ & $(8,9,10,10)$ \\
$\mathrm{C}_{5}$ & $\mathrm{D}_{1}$ & $(7,8,8,9)$ & $(7,8,8,9)$ & $(7,8,8,9)$ \\
& $\mathrm{D}_{2}$ & $(8,9,10,10)$ & $(8,9,10,10)$ & $(8,9,10,10)$ \\
& $\mathrm{D}_{3}$ & $(7,8,8,9)$ & $(8,9,10,10)$ & $(7,8,8,9)$ \\
\hline
\end{tabular}


Table 7

Fuzzy aggregated decision matrix

\begin{tabular}{ccccccccccccc}
\hline & \multicolumn{3}{c}{$\mathrm{x}_{1}$} & \multicolumn{4}{c}{$\mathrm{x}_{2}$} & \multicolumn{4}{c}{$\mathrm{x}_{3}$} \\
& $x_{i j 1}$ & $x_{i j 2}$ & $x_{i j 3}$ & $x_{i j 4}$ & $x_{i j 1}$ & $x_{i j 2}$ & $x_{i j 3}$ & $x_{i j 4}$ & $x_{i j 1}$ & $x_{i j 2}$ & $x_{i j 3}$ & $x_{i j 4}$ \\
\hline $\mathrm{C}_{1}$ & 5.00 & 7.67 & 8.33 & 10.00 & 5.00 & 7.67 & 8.33 & 10.00 & 5.00 & 7.33 & 7.67 & 9.00 \\
$\mathrm{C}_{2}$ & 5.00 & 8.00 & 9.00 & 10.00 & 5.00 & 7.67 & 8.33 & 10.00 & 7.00 & 8.67 & 9.33 & 10.00 \\
$\mathrm{C}_{3}$ & 7.00 & 8.67 & 9.33 & 10.00 & 7.00 & 8.67 & 9.33 & 10.00 & 7.00 & 8.33 & 8.67 & 10.00 \\
$\mathrm{C}_{4}$ & 7.00 & 8.33 & 8.67 & 10.00 & 7.00 & 8.67 & 9.33 & 10.00 & 7.00 & 8.67 & 9.33 & 10.00 \\
$\mathrm{C}_{5}$ & 7.00 & 8.33 & 8.67 & 10.00 & 7.00 & 8.67 & 9.33 & 10.00 & 7.00 & 8.33 & 8.67 & 10.00 \\
\hline
\end{tabular}

During the normalisation of the criteria, $\mathrm{C}_{1}, \mathrm{C}_{2}$ and $\mathrm{C}_{4}$ were considered as benefit-based criteria, while $\mathrm{C}_{3}$ and $\mathrm{C}_{5}$ were taken as cost-based criteria. The weighted normalised values for the portfolio were obtained using the information in Tables (3-8) alongside.

Table 8

Normalised decision matrix

\begin{tabular}{ccccccccccccc}
\hline & \multicolumn{3}{c}{$\mathrm{x}_{1}$} & \multicolumn{4}{c}{$\mathrm{x}_{2}$} & \multicolumn{4}{c}{$\mathrm{x}_{3}$} \\
& $x_{i j 1}$ & $x_{i j 2}$ & $x_{i j 3}$ & $x_{i j 4}$ & $x_{i j 1}$ & $x_{i j 2}$ & $x_{i j 3}$ & $x_{i j 4}$ & $x_{i j 1}$ & $x_{i j 2}$ & $x_{i j 3}$ & $x_{i j 4}$ \\
\hline $\mathrm{C}_{1}$ & 0.50 & 0.77 & 0.83 & 1.00 & 0.50 & 0.77 & 0.83 & 1.00 & 0.50 & 0.73 & 0.77 & 0.90 \\
$\mathrm{C}_{2}$ & 0.50 & 0.80 & 0.90 & 1.00 & 0.50 & 0.77 & 0.83 & 1.00 & 0.70 & 0.87 & 0.93 & 1.00 \\
$\mathrm{C}_{3}$ & 0.50 & 0.54 & 0.58 & 1.00 & 0.50 & 0.54 & 0.58 & 1.00 & 0.50 & 0.58 & 0.60 & 0.71 \\
$\mathrm{C}_{4}$ & 0.50 & 0.83 & 0.87 & 1.00 & 0.70 & 0.87 & 0.93 & 1.00 & 0.70 & 0.87 & 0.93 & 1.00 \\
$\mathrm{C}_{5}$ & 0.50 & 0.58 & 0.60 & 1.00 & 0.50 & 0.54 & 0.58 & 1.00 & 0.50 & 0.58 & 0.60 & 0.71 \\
\hline
\end{tabular}

Table 9

Weighted normalised decision matrix

\begin{tabular}{ccccccccccccc}
\hline & \multicolumn{3}{c}{$\mathrm{x}_{1}$} & \multicolumn{4}{c}{$\mathrm{x}_{2}$} & \multicolumn{4}{c}{$\mathrm{x}_{3}$} \\
& $x_{i j 1}$ & $x_{i j 2}$ & $x_{i j 3}$ & $x_{i j 4}$ & $x_{i j 1}$ & $x_{i j 2}$ & $x_{i j 3}$ & $x_{i j 4}$ & $x_{i j 1}$ & $x_{i j 2}$ & $x_{i j 3}$ & $x_{i j 4}$ \\
\hline $\mathrm{C}_{1}$ & 0.35 & 0.61 & 0.67 & 0.90 & 0.35 & 0.61 & 0.67 & 0.90 & 0.35 & 0.59 & 0.61 & 0.81 \\
$\mathrm{C}_{2}$ & 0.40 & 0.72 & 0.90 & 1.00 & 0.40 & 0.69 & 0.83 & 1.00 & 0.56 & 0.78 & 0.93 & 1.00 \\
$\mathrm{C}_{3}$ & 0.35 & 0.47 & 0.54 & 1.00 & 0.35 & 0.47 & 0.54 & 1.00 & 0.35 & 0.50 & 0.56 & 0.71 \\
$\mathrm{C}_{4}$ & 0.35 & 0.67 & 0.69 & 0.90 & 0.49 & 0.69 & 0.75 & 0.90 & 0.49 & 0.69 & 0.75 & 0.90 \\
$\mathrm{C}_{5}$ & 0.35 & 0.46 & 0.48 & 0.90 & 0.35 & 0.43 & 0.46 & 0.90 & 0.35 & 0.46 & 0.48 & 0.64 \\
\hline
\end{tabular}

Table 10

Distances of the criteria from positive ideal solutions

\begin{tabular}{lccc}
\hline Criterion & $\mathrm{x}_{1}$ & $\mathrm{x}_{2}$ & $\mathrm{x}_{3}$ \\
\hline $\mathrm{C}_{1}$ & 0.6931 & 0.6931 & 0.7790 \\
$\mathrm{C}_{2}$ & 0.4484 & 0.4839 & 0.2464 \\
$\mathrm{C}_{3}$ & 0.9224 & 0.9224 & 0.9476 \\
$\mathrm{C}_{4}$ & 0.6377 & 0.4283 & 0.4283 \\
$\mathrm{C}_{5}$ & 0.9928 & 1.0490 & 1.1104 \\
\hline
\end{tabular}

Table 11

Distances of the criteria from negative ideal solutions

\begin{tabular}{lccc}
\hline Criterion & $\mathrm{x}_{1}$ & $\mathrm{x}_{2}$ & $\mathrm{x}_{3}$ \\
\hline $\mathrm{C}_{1}$ & 1.7531 & 1.7531 & 1.4990 \\
$\mathrm{C}_{2}$ & 2.4884 & 2.3305 & 2.7931 \\
$\mathrm{C}_{3}$ & 1.6276 & 1.6276 & 1.1960 \\
$\mathrm{C}_{4}$ & 1.8577 & 2.0883 & 2.0883 \\
$\mathrm{C}_{5}$ & 1.3759 & 1.3292 & 0.9792 \\
\hline
\end{tabular}


Table 12

Final outputs from the fuzzy TOPSIS method

\begin{tabular}{lccc}
\hline & $\mathrm{x}_{1}$ & $\mathrm{x}_{2}$ & $\mathrm{x}_{3}$ \\
\hline$D_{i}^{+}$ & 3.6944 & 3.5767 & 3.5117 \\
$D_{i}^{-}$ & 9.1027 & 9.1288 & 8.5556 \\
$C C_{i}$ & 0.7113 & 0.7185 & 0.7090 \\
\hline
\end{tabular}

The information in Table 11 was used to implement the COPRAS method that was discussed in section 2.3. The weighted normalised fuzzy numbers were converted into crisp values (Table 13).

Table 13

Crisp values of the criteria for COPRAS analysis

\begin{tabular}{lccc}
\hline Criterion & $\mathrm{x}_{1}$ & $\mathrm{X}_{2}$ & $\mathrm{X}_{3}$ \\
\hline $\mathrm{C}_{1}$ & 0.6304 & 0.6304 & 0.5870 \\
$\mathrm{C}_{2}$ & 0.7451 & 0.7245 & 0.8122 \\
$\mathrm{C}_{3}$ & 0.6114 & 0.6114 & 0.5313 \\
$\mathrm{C}_{4}$ & 0.6442 & 0.7043 & 0.7043 \\
$\mathrm{C}_{5}$ & 0.5719 & 0.5616 & 0.4874 \\
\hline
\end{tabular}

\section{Table 14}

COPRAS outputs for portfolio selection

\begin{tabular}{lccc}
\hline & $\mathrm{X}_{1}$ & $\mathrm{x}_{2}$ & $\mathrm{X}_{3}$ \\
\hline $\mathrm{P}_{\mathrm{j}}$ & 2.0198 & 2.0593 & 2.1035 \\
$\mathrm{R}_{\mathrm{j}}$ & 1.1834 & 1.1731 & 1.0187 \\
$\mathrm{Q}_{\mathrm{j}}$ & 3.0843 & 3.1332 & 3.3401 \\
\hline
\end{tabular}

The utility degree of the various alternatives for the bank portfolio selection was determined using the information in Table 16. In terms of utility degree, the best ranked alternative for the bank portfolio selection problem was $\mathrm{x}_{3}(100 \%)$, while $\mathrm{x}_{2}$ was the second-ranked alternative with a utility degree value of $93.80 \%$. A value of $92.34 \%$ was obtained as the utility degree of $\mathrm{x}_{1}$.

\subsection{A comparison of Fuzzy-TOPSIS and COPRAS results}

The comparison of the results from the fuzzy-TOPSIS and COPRAS methods are shown in Fig. 4. The results have shown that the selection methods gave different ranking orders for bank portfolio selection. In order to obtain the final ranks for the portfolios, the default, fuzzy TOPSIS and COPRAS ranking results were aggregated. Based on the aggregated ranks, the best portfolio for the case study is quick service point $\left(\mathrm{x}_{2}\right)$, while the opening of a branch is the least attract option $\left(\mathrm{x}_{3}\right)$. The results obtained from this study have shown that portfolio selection results should be based on more than one selection methods.

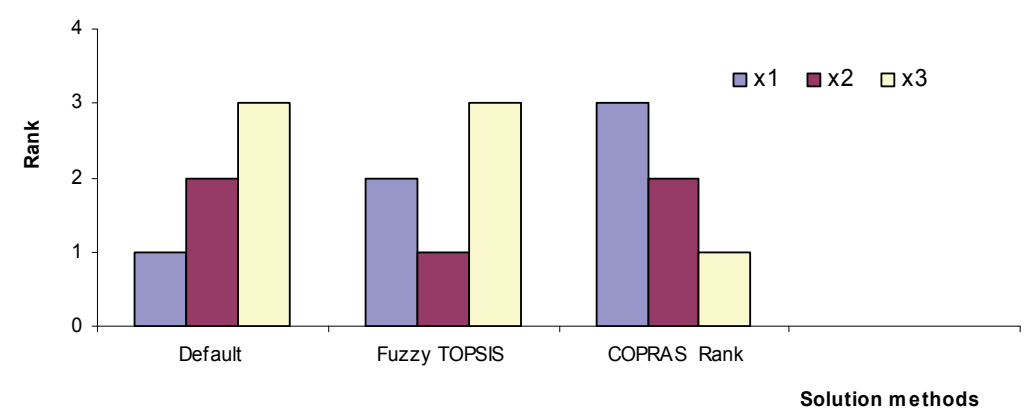

Fig. 3. Comparison of portfolio selection methods 


\section{Conclusions}

The development and application of a multi-criteria framework for bank portfolio selection was pursued in this stud $\dot{\varepsilon}$. This was achieved by proposing a framework that considered fuzzy logic and TOPSIS as a selection tool. The applicability of the proposed framework was verified using information obtained from a bank. Three decision-makers were considered during the proposed framework application. Based on the results obtained, it was observed that the proposed framework has the capacity to identify the best and worst portfolios for a bank.

Furthermore, the results obtained from the fuzzy-TOPSIS method were compared with COPRAS method and decision-makers' intuitions. It was observed that the ranking methods did not give the same results. However, the proposed framework addressed the discrepancies in results by aggregating the various ranks from the ranking methods. The aggregated results were consistent with the fuzzy TOPSIS results.

The consideration of fuzzy axiomatic design principles for bank portfolio could be pursued as a further study.

\section{References}

Agarana, M.C., Bishop, S.A., \& Odetunmibi O.A. (2014). Optimisation of banks loan portfolio management using goal programming technique. International Journal of Research in Applied, Natural and Social Sciences, 2(8), 43-52.

Al-Halaseh, R.H.S., Islam, Md. A., \& Bakar R. (2016). Dynamic portfolio selection: A literature revisit. International Business management, 10(2), 67-77.

Al-Tarawneh, A., \& Khataybeh M. (2015). Portfolio behaviour of commercial banks: the expected utility approach: evidence from Jordan. International Journal of Economics and Financial Issues, 5(2), 312-323.

Anyaeche, C.O., \& Asokeji, T.D. (2016). An integrated fuzzy-based AHP and TOPSIS models in project portfolio selection of banking services, Journal of Nigerian Institute of Industrial Engineers, 5, 19-36.

Anyaeche, C.O., \& Okwara, R.A. (2011). An integer linear programming model for project portfolio selection in a community. International Journal of Engineering Research in Africa, 4, 67-74.

Archer, N.P., \& Ghasemzadeh, F. (1999). An integrated framework for project portfolio selection. International Journal of Project Management, 17(4), 207-216.

Ighravwe, D.E., \& Oke S.A. (2016). A multi-attribute framework for determining the competitive advantages of products for business survival: A fuzzy TOPSIS approach. Total Quality Management and Business Excellence, 1-18. $\quad$ http://dx.doi.org/10.1080/14783363.2016.1234348.

Larson, C. P., Koehlmoos, T. P., Sack, D. A., \& Scaling Up of Zinc for Young Children (SUZY) Project Team. (2011). Scaling up zinc treatment of childhood diarrhoea in Bangladesh: theoretical and practical considerations guiding the SUZY Project. Health policy and planning, 27(2), 102-114.

Madi, E.N., \& Tap, A.O.M. (2011). Fuzzy TOPSIS method in the selection of investment boards by incorporating operational risks. Proceedings of the World Congress on Engineering 2011, WCE 2011, July 6 - 8, 2011, London, U.K.

Malek, H., Emamverdi, G., \& Kashani, M.S. (2014). Selecting an optimal resource allocation model to consumptions in banks of Iran. International Journal of Academic Research in Business and Social Sciences, 4(3), 204-213.

Markowitz, H. M. (1968). Portfolio selection: efficient diversification of investments (Vol. 16). Yale university press.

McFarlan, F.W. (1981). Portfolio approach to information systems. Harvard Business Review, SeptOct, 142-150. 
Misra, A.K. (2011). Optimisation of return under risk constraint: An application on Indian banks. 2011 International Conference on Financial Management and Economics, IPEDR, Vol.11 (2011), IACSIT Press, Singapore.

Oyatoye, E.O., Okpokpo, G.U., \& Adekoya, G.A. (2010). An application of AHP to investment portfolio selection in the banking sector of the Nigerian capital market. Journal of Economics and International Finance, 2(12), 321.

Paris, F. (2005). Selecting an optimal portfolio of consumer loans by applying the state preference approach. European Journal of Operational Research, 163(1), 230-241.

Pinto, J.K., \& Mantel, S.J. (1990). The causes of project failure. IEEE Transactions on Engineering Management, 37(4), 269-276.

Saaty, T. L. (1980). Analytic hierarchy process. John Wiley \& Sons, Ltd.

Saunders, D., Xiouros, C., \& Zenios, S. (2007). Credit risk optimisation using factor model. Annals of Operations Research, 152(1), 49-77.

Shemshadi, A., Shirazi, H., Toreihi, M., \& Tarokh, M. J. (2011). A fuzzy VIKOR method for supplier selection based on entropy measure for objective weighting. Expert Systems with Applications, 38(10), 12160-12167.

Sirignano, J. A., Tsoukalas, G., \& Giesecke, K. (2016). Large-scale loan portfolio selection. Operations Research, 64(6), 1239-1255

Telsang, M. (2012). Industrial Engineering and Production Management. 11th ed. New Delhi: S. Chand \& Company Ltd.

Wang, Y. M., \& Elhag, T. M. (2006). Fuzzy TOPSIS method based on alpha level sets with an application to bridge risk assessment. Expert systems with applications, 31(2), 309-319.

Westney, R.E. (2004). Managing the Engineering and Construction of Small Projects. Marcel Dekker, Inc.

Wideman, R.M. (1995). Criteria for a project-management body of knowledge. International Journal of Management, 13(2), 71-75.

Wit, A. (1988). Measurement of project success. International Journal of Project Management, 6(3), 164-170

Yoon, K. P., \& Hwang, C. L. (1995). Multiple attribute decision making: an introduction (Vol. 104). Sage publications.

Zavadskas, E.K., \& Kaklauskas, A. (1996). Multiple Criteria Evaluation of Buildings. Technika, Vilnius (in Lithuanian).

Zavadskas, E.K., Turskis, Z., Tamosaitiene, J., \& Marina, V. (2008). Selection of Construction Project Managers by Applying COPRAS-G Method. The 8th International Conference Reliability and Statistics in Transportation and Communication - 2008, 344-350.

Zolfani, S.H., Rezaeiniya, N., Aghdaie, M.H., \& Zavadskas, E.K. (2012). Quality control manager selection based on AHP-COPRAS-G methods: a case in Iran. Economic Research-Ekonomska Istrazivanja, 25(1), 72-86.

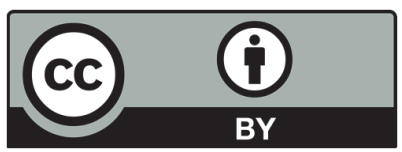

(C) 2017 by the authors; licensee Growing Science, Canada. This is an open access article distributed under the terms and conditions of the Creative Commons Attribution (CC-BY) license (http://creativecommons.org/licenses/by/4.0/). 